\title{
Relationships of subjectively assessed wool and conformation traits with objectively measured wool and live weight traits in the Tygerhoek Merino flock
}

\author{
P.A. Matebesi ${ }^{1,2}$, J.B. van Wyk ${ }^{2}$ and S.W.P. Cloete ${ }^{3,4 \#}$ \\ ${ }^{1}$ Department of Animal Sciences, National University of Lesotho, P.O. Roma 180, Lesotho \\ ${ }^{2}$ Department of Animal, Wildlife and Grassland Sciences, University of the Free State, P.O. Box 339, \\ Bloemfontein 9300, South Africa \\ ${ }^{3}$ Department of Animal Sciences, Stellenbosch University, Private Bag X1, Matieland 7602, South Africa \\ ${ }^{4}$ Institute for Animal Production: Elsenburg, Private Bag X1, Elsenburg 7609, South Africa
}

\begin{abstract}
Records of the Tygerhoek Merino resource flock were used to estimate genetic, phenotypic and environmental parameters between subjective wool and conformation traits with objective wool and live weight traits. The database contained records of 4495 animals, the progeny of 449 sires and 1831 dams, and born from 1989 to 2004. On the genetic level $\left(\mathrm{r}_{\mathrm{g}}\right)$ live weight was favourably related to regularity of crimp (ROC) (0.20), woolly face score (WFS) (0.21), general head conformation (GEN) (0.67), conformation of the hind legs (HOCKS) (0.36), conformation of the front legs (FQ) (0.42), topline (TOPL) (0.25) and total fold score (TOT). Estimates of $\mathrm{r}_{\mathrm{g}}$ were favourable for clean yield with wool quality (QUAL) (0.30), wool colour (COL) (0.45), wool oil (OIL) (-0.44), staple formation (STAPL), belly and points (BANDP) (0.24), face cover score (FCS) (0.18), GEN (0.25), HOCKS (0.19), TOT (-0.26) and FQ (0.18). Clean fleece weight (CFW) was favourable correlated to QUAL (0.18), STAPL (0.39), BANDP (0.48) and GEN (0.23). Staple length was favourably related to COL (0.16), BANDP (0.40) and WFS (0.16) and negatively related to OIL (-0.33). Staple strength was favourable correlated to ROC (0.33) and FQ (0.39). Fibre diameter was favourable correlated with QUAL (-0.32), ROC (-0.28), FCS (-0.32), pastern score (PS) (-0.16) and TOPL (-0.18). Coefficient of variation of fibre diameter (CVFD) was favourably correlated with QUAL (-0.50), ROC (-0.73), HOCKS (-0.17), FQ (-0.33) and TOPL (-0.25). In contrast, unfavourable correlations occurred for SS with TOT (0.25), for FD with STAPL (0.59), BANDP (0.37), HOCKS (0.13) and TOT (0.13). Other unfavourable genetic correlations were between CFW and TOT (0.28) and between CVFD and STAPL (0.49). The results showed that selection for LW and objective wool traits will not seriously compromise subjective wool and conformation traits, barring a few exceptions.
\end{abstract}

Keywords: Correlations, linearly assessed traits, subjective traits, conformation, wool traits, body weight

\# Corresponding author. E-mail: schalkc@elsenburg.com

\section{Introduction}

Construction of an appropriate breeding plan for a woolled sheep enterprise requires knowledge of genetic parameters and correlations between traits of economic importance. Researchers estimated genetic parameters for production traits in the past decades, as were reviewed by Fogarty (1995) and by Snyman et al. (1995). More recently genetic parameters for sheep were reviewed by Safari et al. (2005). Traditionally, however, Merino sheep have been selected using a classing system that relied on visual differences, with a believe that subjective traits are either an important part of production or are related to qualitative or quantitative traits of economic importance (Morley, 1955; Young et al., 1963; Cloete et al., 1992; Lewer et al., 1995). In fact, these traits are often seen as important for the economic viability of farms (Olivier et al., 2006a) and were in some instances used exclusively for the selection and culling of breeding stock (Lewer et al., 1995; Snyman \& Olivier, 2002). Previous studies on South African Merino and Afrino sheep also indicated that emphasis is placed on subjectively assessed wool and conformation traits in selecting breeding sires and dams. Animals are thus culled on the basis of these traits, potentially to the detriment of the economically important traits, such as fibre diameter, fleece weight, staple strength, live weight and reproduction (Snyman \& Olivier, 2002; Olivier et al., 2006a). However, Gregory (1982) emphasised that knowledge of genetic relationships for these traits with economically important wool and 
body traits is essential to enable prediction of how selection on these traits will affect traits of economic importance.

Phenotypic (Cloete et al., 1992; Crook et al., 1994) and genetic (Lewer et al., 1995; Snyman \& Olivier, 2002; Naidoo et al., 2004; Brown et al., 2006; Olivier et al., 2006a; b) correlations of subjective wool and conformation traits with objective traits of economic importance such as fibre diameter, clean fleece weight and live-weight were reported in literature. Apart from these references, information is limited about the genetic, phenotypic and the environmental relationships of these subjectively assessed traits with live weight and objectively measured wool traits. Moreover, information on maternal correlations for subjectively assessed wool and conformation traits with objective wool traits and live weight was lacking in the literature. Therefore correlations (genetic, phenotypic, environmental and maternal) were estimated on six subjective body conformation and nine subjective wool traits to enable the prediction of the direction and magnitude of genetic progress of economically important traits in Merino sheep, when selection of breeding sires and dams depends largely on subjectively assessed wool and conformation traits.

\section{Materials and Methods}

Data utilised in the present study for live weight and the objective wool traits were similar to that described by Matebesi et al. (2009a) and consisted of records of 4495 animals, the progeny of 449 sires and 1831 dams. The animals were born between 1989 and 2004 on the Tygerhoek experimental farm, near Riviersonderend in the Western Cape Province of South Africa. Objectively measured traits included in the analysis were 16-months live weight (LW), greasy fleece weight (GFW), clean fleece weight (CFW), clean yield (CY), fibre diameter (FD), staple length (SL), staple strength (SS), coefficient of variation of fibre diameter (CVFD) and standard deviation of fibre diameter (SDFD). Subjective wool and conformation traits included in the analysis were assessed according to a linear scale ranging from 1 - 50 (Olivier et al., 1987) at 14 - 16 months of age as described by Matebesi et al. (2009b). Subjective wool traits included wool quality (QUAL), regularity of crimp (ROC), wool colour (COL), wool oil or yolk (OIL), staple formation (STAPL), belly and points (BANDP), woolly face score (WFS), face cover score (FCS) and pigmentation (PIGM). Subjective conformation traits included pastern score (PS), general head conformation (GEN), front quarters (FQ), topline (TOPL), total fold score (TOT) and hocks (HOCKS).

The ASREML programme of Gilmour et al. (2002) was used to estimate the correlations among the traits by fitting two-trait animal models. The two-trait animal models included all the random components shown to be significant in the single-trait analyses (Matebesi et al., 2009a; b). A model with the direct additive effect as the only random effect (Model 1) was fitted for CY, SL, SS, CVFD, SDFD, FCS, PIGM, WFS, OIL, STAPL, BANDP, HOCKS, FQ, TOPL and TOT while Model 3 (direct and maternal additive effects as well as the covariance between them) were used for QUAL, COL, ROC and PS. Model 5 (direct additive and maternal additive effects, the covariance between animal effects as well as the dam permanent environmental effect) fitted the data best for GFW and CFW while Model 6 (direct additive effects and dam permanent environmental effects) was the most appropriate model for GEN.

\section{Results and Discussion}

Descriptive statistics of data used for the analysis of objectively measured and subjectively assessed traits in Tygerhoek Merino sheep can be obtained from Matebesi et al. (2009a; b). Genetic, phenotypic, maternal and environmetal correlations between subjective wool and conformation and objective traits are presented in Tables 1, 2, 3 and Table 4, respectively. The genetic correlations $\left(r_{\mathrm{g}}\right)$ between subjectively assessed wool traits and objectively measured traits were moderate to high and variable in sign.

At the genetic level, LW was positively correlated with ROC (0.20) and with WFS (0.20) (Table 1). These correlations were favourable and suggested that heavier sheep are likely to have more even fleeces and more open faces. GFW was unfavourably correlated to COL $(-0.19)$ in the present study, suggesting that sheep with a higher GFW had more yellow wool (Table 1). Brown et al. (2006) also reported unfavourable correlations between GFW and COL that ranged from 0.17 to 0.34 for the Australian Merino (their lowest colour number represented white wool while the current study reports the lowest number being yellow wool). However, these results disagree with that of Lewer et al. (1995) who reported a favourable genetic correlation of -0.16 for Western Australian Merinos. Other studies attributed these conflicting results to environment in which the sheep were managed which had an effect on the source of increased wool colour 
(Brown et al., 2006). Corresponding correlations with STAPL and BANDP were favourable. As a result, selection for STAPL and BANDP would likely result in an increased GFW. GFW was positively related to OIL.

There were favourable genetic correlations of CFW with QUAL, STAPL and BANDP, as suggested by moderate and positive genetic correlations. Selection for CFW would generally result in sheep with wool of good quality and higher scores for STAPL and BANDP. However, selection for CFW should be done with caution as this might lead to breeding stock with excessive wool oil, as suggested by the significant and positive genetic correlation of 0.28 between CFW and OIL. Similar positive genetic correlations for corresponding traits were reported by Naidoo et al. (2004) on a smaller data set. However, Olivier et al. (2006a) reported higher genetic correlations for CFW with QUAL (0.40) and for CFW with STAPL (0.57). On the genetic level CY was favourably related to QUAL, COL, STAPL, BANDP and FCS. These correlations suggested that sheep with a higher percentage of clean wool are likely to have whiter wool of good quality, their faces will have a softer handle and they will have higher scores for STAPL and BANDP. These results corresponded fairly well with corresponding correlations reported in the literature (Lewer et al., 1995; Naidoo et al., 2004). The genetic correlation for CY with OIL was moderate and negative (-0.44). Naidoo et al. (2004) reported a similar genetic correlation between CY and OIL (-0.45) for the same Merino flock, but using a smaller data set.

Maintaining or decreasing FD is a major component of the overall breeding objective in the Merino breed. Selection for sheep with a good quality wool that have more even fleeces and softer wool covering of the face would likely result in a reduced FD in breeding stock, as suggested by favourable genetic correlations of FD with QUAL (-0.32), ROC (-0.28) and FCS (-0.30) (see Table 1). Similar genetic correlations were reported in the literature (Snyman \& Olivier, 2002; Naidoo et al., 2004; Olivier et al., 2006b), though the correlations were somewhat higher for Afrino sheep (Snyman \& Olivier, 2002). Corresponding correlations of FD with STAPL and BANDP were unfavourable and moderate to high, suggesting that selection of sheep with higher scores for BANDP and for STAPL will probably result in sheep with a higher fibre diameter. Similar genetic correlations were obtained for South African Merino sheep (Naidoo et al., 2004; Olivier et al., 2006b).

The genetic relationship between CVFD and SDFD was high (0.87) (Matebesi et al., 2008a). Therefore, it is not surprising that correlations for CVFD and SDFD with subjectively assessed wool traits followed similar patterns (Table 1). Genetic correlations of CVFD and SDFD with QUAL and ROC were favourable and moderate to high. Corresponding correlations with STAPL were unfavourable and high. These results suggested that sheep with higher scores for QUAL and ROC had lower scores for STAPL and their crimps showed less variation within staples and across the fleece. A previous study on the same Merino flock reported similar results for the correlations of CVFD with QUAL, ROC and STAPL (Naidoo et al., 2004). SDFD was also unfavourably correlated to BANDP.

On a genetic basis, SL was moderately and favourably related to COL, BANDP and WFS and negatively related to OIL. These results indicated that sheep with longer staples had better scores for COL, BANDP and WFS as well as lower scores for OIL. The economic implications for Merino sheep breeding programmes are that, sheep with longer staples are likely to have whiter wool, with better scores for BANDP and more open faces. While Naidoo et al. (2004) found no significant genetic correlations between SL and the respective subjective wool traits, Snyman \& Olivier (2002) reported a negative correlation of -0.19 for SL with ROC in Afrino sheep.

Furthermore, Olivier et al. (2006b) reported a significant correlation between SL and QUAL (0.31) and a nonsignificant correlation of SL with STAPL (0.02). Of all the subjectively assessed wool traits, only ROC was related to SS, as suggested by a significant genetic correlation of 0.33 . This result suggested that sheep with wool that has a very regular crimp were less likely to produce tender wool. It is noteworthy that PIGM was not related to any of the objective wool traits or live-weight in the present study. Therefore, selection for LW and objective wool traits would not increase the risk of a higher proportion of dark fibres in the wool of breeding stock. 
Table 1 Genetic correlations ( \pm s.e.) between subjectively and objectively measured wool and conformation traits in Tygerhoek Merino flock

\begin{tabular}{|c|c|c|c|c|c|c|c|c|c|}
\hline \multirow{2}{*}{$\begin{array}{l}\text { Subjective } \\
\text { traits }\end{array}$} & \multicolumn{9}{|c|}{ Live weight and objective wool traits } \\
\hline & LW & GFW & CFW & CY & FD & SL & SS & CVFD & SDFD \\
\hline \multicolumn{10}{|c|}{ Subjective wool traits } \\
\hline QUAL & $-0.01 \pm 0.07$ & $0.10 \pm 0.06$ & $0.18^{*} \pm 0.06$ & $0.30 * \pm 0.05$ & $-0.32 * \pm 0.05$ & $-0.01 \pm 0.08$ & $0.17 \pm 0.12$ & $-0.50 * \pm 0.06$ & $-0.62 * \pm 0.05$ \\
\hline ROC & $0.20 * \pm 0.08$ & $0.02 \pm 0.08$ & $0.01 \pm 0.07$ & $0.06 \pm 0.07$ & $-0.28 * \pm 0.08$ & $0.09 \pm 0.08$ & $0.33^{*} \pm 0.14$ & $-0.73 * \pm 0.06$ & $-0.81 * \pm 0.05$ \\
\hline COL & $-0.03 \pm 0.07$ & $-0.19 * \pm 0.07$ & $-0.02 \pm 0.07$ & $0.45 * \pm 0.05$ & $-0.09 \pm 0.06$ & $0.16 * \pm 0.07$ & $0.17 \pm 0.12$ & $-0.08 \pm 0.07$ & $-0.14 * \pm 0.07$ \\
\hline OIL & $-0.15 \pm 0.08$ & $0.48 * \pm 0.08$ & $0.28 * \pm 0.08$ & $-0.44 * \pm 0.06$ & $-0.02 \pm 0.07$ & $-0.33 * \pm 0.08$ & $0.10 \pm 0.13$ & $0.05 \pm 0.08$ & $0.03 \pm 0.07$ \\
\hline STAPL & $-0.01 \pm 0.09$ & $0.35 * \pm 0.08$ & $0.39 * \pm 0.08$ & $0.21 * \pm 0.07$ & $0.59 * \pm 0.06$ & $0.12 \pm 0.08$ & $-0.05 \pm 0.14$ & $0.49 * \pm 0.07$ & $0.71 * \pm 0.05$ \\
\hline BANDP & $0.01 \pm 0.08$ & $0.42 * \pm 0.08$ & $0.48 * \pm 0.07$ & $0.24 * \pm 0.06$ & $0.37 * \pm 0.06$ & $0.40 * \pm 0.07$ & $0.08 \pm 0.13$ & $0.04 \pm 0.08$ & $0.20 * \pm 0.07$ \\
\hline WFS & $0.21 * \pm 0.07$ & $-0.00 \pm 0.07$ & $0.00 \pm 0.07$ & $0.03 \pm 0.05$ & $0.03 \pm 0.06$ & $0.16^{*} \pm 0.06$ & $-0.10 \pm 0.11$ & $-0.05 \pm 0.06$ & $-0.02 \pm 0.06$ \\
\hline FCS & $0.01 \pm 0.10$ & $0.04 \pm 0.11$ & $0.12 \pm 0.10$ & $0.18 * \pm 0.08$ & $-0.30 * \pm 0.08$ & $-0.02 \pm 0.10$ & $0.06 \pm 0.16$ & $-0.05 \pm 0.09$ & $-0.18 * \pm 0.09$ \\
\hline PIGM & $-0.00 \pm 0.07$ & $0.09 \pm 0.07$ & $0.06 \pm 0.07$ & $-0.00 \pm 0.05$ & $0.09 \pm 0.05$ & $0.00 \pm 0.06$ & $0.08 \pm 0.11$ & $-0.06 \pm 0.06$ & $-0.01 \pm 0.06$ \\
\hline \multicolumn{10}{|c|}{ Subjective conformation traits } \\
\hline PS & $0.18 \pm 0.10$ & $-0.13 \pm 0.10$ & $0.09 \pm 0.09$ & $0.12 * \pm 0.09$ & $-0.16 * \pm 0.08$ & $-0.20 \pm 0.11$ & $0.13 \pm 0.19$ & $-0.01 \pm 0.11$ & $-0.12 \pm 0.11$ \\
\hline GEN & $0.67 * \pm 0.05$ & $0.11 \pm 0.08$ & $0.23 * \pm 0.07$ & $0.25 * \pm 0.05$ & $-0.06 \pm 0.06$ & $0.31 * \pm 0.06$ & $0.05 \pm 0.13$ & $-0.06 \pm 0.07$ & $-0.06 \pm 0.06$ \\
\hline HOCKS & $0.36 * \pm 0.07$ & $-0.01 \pm 0.09$ & $0.03 \pm 0.08$ & $0.19 * \pm 0.06$ & $0.13^{*} \pm 0.06$ & $0.09 \pm 0.08$ & $0.20 \pm 0.13$ & $-0.17 * \pm 0.07$ & $-0.07 \pm 0.07$ \\
\hline FQ & $0.42 * \pm 0.09$ & $0.07 \pm 0.11$ & $0.16 \pm 0.11$ & $0.18 * \pm 0.08$ & $0.08 \pm 0.08$ & $0.07 \pm 0.10$ & $0.39 * \pm 0.17$ & $-0.33 * \pm 0.09$ & $-0.20 * \pm 0.09$ \\
\hline TOPL & $0.25 * \pm 0.10$ & $-0.34 * \pm 0.11$ & $-0.29 * \pm 0.11$ & $0.03 \pm 0.09$ & $-0.18 * \pm 0.09$ & $0.14 \pm 0.10$ & $0.04 \pm 0.18$ & $-0.25 * \pm 0.10$ & $-0.27 * \pm 0.09$ \\
\hline TOT & $-0.23 * \pm 0.07$ & $0.48 * \pm 0.06$ & $0.28 * \pm 0.07$ & $-0.26 * \pm 0.05$ & $0.13 * \pm 0.06$ & $-0.43 * \pm 0.06$ & $0.25 * \pm 0.12$ & $0.03 \pm 0.07$ & $0.06 \pm 0.06$ \\
\hline
\end{tabular}

$\overline{\mathrm{QUAL}}=$ wool quality, ROC $=$ regularity of crimp, $\mathrm{COL}=$ wool colour, OIL $=$ wool oil, STAPL $=$ staple formation, BANDP $=$ belly and points, WFS $=$ woolly face score, FCS = face cover score, PIGM = pigmentation, GEN $=$ general head conformation, HOCKS $=$ hocks, $\mathrm{FQ}=$ front quarters, TOPL $=$ topline, TOT $=$ total fold score, $\mathrm{LW}=$ live weight, GFW = greasy fleece weight, $\mathrm{CFW}=$ clean fleece weight, $\mathrm{CY}=$ clean yield, $\mathrm{SL}=$ staple length, $\mathrm{SS}=\mathrm{staple}$ strength, $\mathrm{FD}=$ fibre diameter, CVFD = coefficient of variation of fibre diameter, SDFD = standard deviation of fibre diameter.

$*$ = significant correlation. 
Table 2 Phenotypic correlations ( \pm s.e.) between subjectively assessed wool and conformation with objective wool traits and live weight in Tygerhoek Merino flock

\begin{tabular}{|c|c|c|c|c|c|c|c|c|c|}
\hline \multirow{2}{*}{$\begin{array}{l}\text { Subjective } \\
\text { traits }\end{array}$} & \multicolumn{9}{|c|}{ Live weight and objective wool traits } \\
\hline & LW & GFW & CFW & CY & FD & SL & SS & CVFD & SDFD \\
\hline QUAL & $0.04 * \pm 0.02$ & $0.05 * \pm 0.02$ & $0.09 * \pm 0.02$ & $0.17 * \pm 0.02$ & $-0.20 * \pm 0.02$ & $0.01 \pm 0.03$ & $0.07 * \pm 0.03$ & $-0.34 * \pm 0.02$ & $-0.40 * \pm 0.02$ \\
\hline ROC & $0.08 * \pm 0.02$ & $-0.04 * \pm 0.01$ & $-0.03 \pm 0.02$ & $0.05 * \pm 0.02$ & $-0.17 * \pm 0.02$ & $-0.01 \pm 0.02$ & $0.09 * \pm 0.02$ & $-0.34 * \pm 0.02$ & $-0.40 * \pm 0.02$ \\
\hline COL & $0.03 \pm 0.02$ & $-0.09 * \pm 0.01$ & $-0.02 \pm 0.02$ & $0.25 * \pm 0.02$ & $-0.06 * \pm 0.02$ & $0.06 * \pm 0.02$ & $0.06 * \pm 0.02$ & $-0.11 * \pm 0.02$ & $-0.13 * \pm 0.02$ \\
\hline OIL & $-0.01 \pm 0.02$ & $0.24 * \pm 0.02$ & $0.16^{*} \pm 0.02$ & $-0.24 * \pm 0.02$ & $-0.01 \pm 0.02$ & $-0.10 * \pm 0.02$ & $-0.01 \pm 0.02$ & $0.07 * \pm 0.02$ & $0.06 * \pm 0.02$ \\
\hline STAPL & $0.11 * \pm 0.02$ & $0.24 * \pm 0.02$ & $0.03 \pm 0.02$ & $0.09 * \pm 0.02$ & $0.32 * \pm 0.02$ & $0.11 * \pm 0.02$ & $0.02 \pm 0.03$ & $0.20 * \pm 0.02$ & $0.34 * \pm 0.02$ \\
\hline BANDP & $0.14 * \pm 0.02$ & $0.33 * \pm 0.01$ & $0.34 * \pm 0.01$ & $0.13 * \pm 0.02$ & $0.25 * \pm 0.02$ & $0.23^{*} \pm 0.02$ & $0.13 \pm 0.03$ & $-0.04 * \pm 0.02$ & $0.12 * \pm 0.02$ \\
\hline WFS & $0.13 * \pm 0.02$ & $-0.01 \pm 0.02$ & $-0.01 \pm 0.02$ & $-0.01 \pm 0.04$ & $0.07 * \pm 0.02$ & $0.13^{*} \pm 0.02$ & $-0.01 \pm 0.02$ & $-0.10 * \pm 0.02$ & $-0.03 \pm 0.02$ \\
\hline FCS & $0.02 \pm 0.02$ & $0.07 * \pm 0.02$ & $0.08 * \pm 0.02$ & $0.01 \pm 0.03$ & $-0.09 * \pm 0.02$ & $0.02 \pm 0.02$ & $-0.03 \pm 0.02$ & $-0.04 * \pm 0.02$ & $-0.06 * \pm 0.02$ \\
\hline PIGM & $0.04 * \pm 0.02$ & $0.03 \pm 0.02$ & $0.03 \pm 0.02$ & $-0.02 \pm 0.04$ & $0.04 * \pm 0.02$ & $0.02 \pm 0.02$ & $0.01 \pm 0.03$ & $0.00 \pm 0.02$ & $0.01 \pm 0.02$ \\
\hline PS & $0.04 * \pm 0.02$ & $0.03 \pm 0.02$ & $0.04 * \pm 0.02$ & $0.03 \pm 0.02$ & $-0.03 \pm 0.02$ & $-0.03 \pm 0.02$ & $0.05 \pm 0.03$ & $-0.02 \pm 0.02$ & $-0.01 \pm 0.02$ \\
\hline GEN & $0.55 * \pm 0.01$ & $0.28 * \pm 0.02$ & $0.30 * \pm 0.02$ & $0.12 * \pm 0.02$ & $0.11 * \pm 0.02$ & $0.24 * \pm 0.02$ & $0.07 * \pm 0.03$ & $-0.10 * \pm 0.02$ & $-0.04 * \pm 0.02$ \\
\hline HOCKS & $0.28 * \pm 0.02$ & $0.10 * \pm 0.02$ & $0.11 * \pm 0.02$ & $0.07 * \pm 0.02$ & $0.12 * \pm 0.02$ & $0.09 * \pm 0.02$ & $0.07 * \pm 0.03$ & $-0.14 * \pm 0.02$ & $-0.05^{*} \pm 0.02$ \\
\hline $\mathrm{FQ}$ & $0.29 * \pm 0.02$ & $0.12 * \pm 0.02$ & $0.14 * \pm 0.02$ & $0.07 * \pm 0.02$ & $0.10 * \pm 0.02$ & $0.10 * \pm 0.02$ & $0.11 * \pm 0.03$ & $-0.13 * \pm 0.02$ & $-0.06 * \pm 0.02$ \\
\hline TOPL & $0.21 * \pm 0.02$ & $-0.01 \pm 0.01$ & $-0.00 \pm 0.02$ & $0.04 * \pm 0.02$ & $0.03 \pm 0.02$ & $0.08 * \pm 0.02$ & $0.03 \pm 0.03$ & $-0.10 * \pm 0.02$ & $-0.06 * \pm 0.02$ \\
\hline TOT & $-0.00 \pm 0.02$ & $0.34 * \pm 0.02$ & $0.25 * \pm 0.02$ & $-0.17 * \pm 0.02$ & $0.05^{*} \pm 0.02$ & $-0.19 * \pm 0.02$ & $-0.02 \pm 0.03$ & $0.11^{*} \pm 0.02$ & $0.12 * \pm 0.02$ \\
\hline
\end{tabular}

See Table 1 for abbreviations.

Table 3 Maternal correlations ( \pm s.e.) between subjectively and objectively measured wool and conformation traits in Tygerhoek Merino flock

\begin{tabular}{|c|c|c|c|c|c|c|c|c|c|}
\hline \multirow{2}{*}{$\begin{array}{l}\text { Subjective } \\
\text { traits }\end{array}$} & \multicolumn{9}{|c|}{ Live weight and objective wool traits } \\
\hline & LW & GFW & CFW & CY & FD & SL & SS & CVFD & SDFD \\
\hline \multicolumn{10}{|c|}{ Subjective wool traits } \\
\hline QUAL & $0.17 \pm 0.17$ & $0.06 \pm 0.13$ & $0.09 \pm 0.13$ & - & $0.21 \pm 0.22$ & - & - & - & - \\
\hline ROC & $0.14 \pm 0.23$ & $0.03 \pm 0.16$ & $0.04 \pm 0.15$ & - & $0.23 \pm 0.28$ & - & - & - & - \\
\hline COL & $0.02 \pm 0.15$ & $0.07 \pm 0.12$ & $0.15 \pm 0.12$ & - & $0.12 \pm 0.17$ & - & - & - & - \\
\hline \multicolumn{10}{|c|}{ Subjective conformation traits } \\
\hline PS & $0.16 \pm 0.19$ & $0.15 \pm 0.14$ & $0.18 \pm 0.14$ & - & $-0.08 \pm 0.22$ & - & - & - & - \\
\hline GEN & $0.74 * \pm 0.01$ & $0.65^{*} \pm 0.20$ & $0.59 * \pm 0.20$ & -- & $0.40 \pm 0.24$ & - & - & - & - \\
\hline
\end{tabular}

See Table 1 for abbreviations. 
Table 4 Environmental correlations ( \pm s.e.) between subjectively assessed wool and conformation with objective wool traits and live weight in Tygerhoek Merino flock

\begin{tabular}{|c|c|c|c|c|c|c|c|c|c|}
\hline \multirow{2}{*}{$\begin{array}{l}\text { Subjective } \\
\text { traits } \\
\end{array}$} & \multicolumn{9}{|c|}{ Live weight and objective wool traits } \\
\hline & LW & GFW & CFW & CY & FD & SL & SS & CVFD & SDFD \\
\hline QUAL & $0.06 * \pm 0.03$ & $0.01 \pm 0.03$ & $0.02 \pm 0.03$ & $0.17 * \pm 0.02$ & $-0.11 * \pm 0.04$ & $0.01 \pm 0.03$ & $0.04 \pm 0.04$ & $-0.20 * \pm 0.04$ & $-0.22 * \pm 0.04$ \\
\hline ROC & $0.02 \pm 0.03$ & $-0.08 \pm 0.03$ & $-0.06 * \pm 0.03$ & $0.05 * \pm 0.02$ & $-0.14 * \pm 0.03$ & $-0.04 \pm 0.03$ & $0.03 \pm 0.04$ & $-0.14 * \pm 0.04$ & $-0.20 * \pm 0.03$ \\
\hline COL & $0.06 * \pm 0.03$ & $-0.07 * \pm 0.03$ & $-0.04 \pm 0.03$ & $0.25 * \pm 0.02$ & $-0.05 \pm 0.04$ & $0.02 \pm 0.03$ & $0.03 \pm 0.04$ & $-0.14 * \pm 0.04$ & $-0.15 * \pm 0.04$ \\
\hline OIL & $0.05 \pm 0.03$ & $0.18 * \pm 0.02$ & $0.12 * \pm 0.03$ & $-0.24 * \pm 0.02$ & $-0.00 \pm 0.03$ & $-0.02 \pm 0.03$ & $-0.03 \pm 0.04$ & $0.09 * \pm 0.04$ & $0.09 * \pm 0.04$ \\
\hline STAPL & $0.16^{*} \pm 0.03$ & $0.21 * \pm 0.02$ & $0.21 * \pm 0.02$ & $0.09 * \pm 0.02$ & $0.19 * \pm 0.03$ & $0.10 * \pm 0.03$ & $0.04 \pm 0.04$ & $0.04 \pm 0.04$ & $0.15^{*} \pm 0.03$ \\
\hline BANDP & $0.20 * \pm 0.03$ & $0.31 * \pm 0.02$ & $0.31 * \pm 0.02$ & $0.13^{*} \pm 0.02$ & $0.20 * \pm 0.03$ & $0.16^{*} \pm 0.03$ & $0.14^{*} \pm 0.04$ & $-0.03 \pm 0.04$ & $0.09 * \pm 0.04$ \\
\hline WFS & $0.08 * \pm 0.03$ & $-0.01 \pm 0.03$ & $-0.01 \pm 0.03$ & $0.01 \pm 0.02$ & $0.11 * \pm 0.04$ & $0.10 * \pm 0.04$ & $0.04 \pm 0.04$ & $-0.10 * \pm 0.05$ & $-0.04 \pm 0.04$ \\
\hline FCS & $0.03 \pm 0.03$ & $0.08 * \pm 0.02$ & $0.08 * \pm 0.02$ & $0.06 * \pm 0.02$ & $-0.01 \pm 0.03$ & $0.04 \pm 0.03$ & $-0.05 \pm 0.04$ & $-0.04 \pm 0.04$ & $-0.01 \pm 0.04$ \\
\hline PIGM & $0.06 * \pm 0.03$ & $0.01 \pm 0.03$ & $0.02 \pm 0.03$ & $-0.01 \pm 0.02$ & $-0.02 \pm 0.04$ & $0.04 \pm 0.03$ & $-0.01 \pm 0.04$ & $0.07 \pm 0.05$ & $0.04 \pm 0.04$ \\
\hline PS & $-0.01 \pm 0.03$ & $0.07 * \pm 0.03$ & $0.07 * \pm 0.03$ & $-0.01 \pm 0.03$ & $0.05 \pm 0.03$ & $0.02 \pm 0.03$ & $0.09 * \pm 0.04$ & $-0.03 \pm 0.04$ & $0.03 \pm 0.04$ \\
\hline GEN & $0.45 * \pm 0.03$ & $0.35 * \pm 0.03$ & $0.32 * \pm 0.03$ & $-0.01 \pm 0.04$ & $0.27 * \pm 0.04$ & $0.20 * \pm 0.03$ & $0.12 \pm 0.05$ & $-0.16 * \pm 0.05$ & $-0.01 \pm 0.04$ \\
\hline HOCKS & $0.25 * \pm 0.03$ & $0.16^{*} \pm 0.03$ & $0.15^{*} \pm 0.03$ & $-0.04 \pm 0.04$ & $0.12 * \pm 0.04$ & $0.08 * \pm 0.03$ & $0.03 \pm 0.04$ & $-0.12 * \pm 0.04$ & $-0.04 \pm 0.04$ \\
\hline $\mathrm{FQ}$ & $0.28 * \pm 0.03$ & $0.14^{* \pm 0.03}$ & $0.15 * \pm 0.03$ & $0.03 \pm 0.03$ & $0.13^{*} \pm 0.03$ & $0.10 * \pm 0.03$ & $0.06 \pm 0.04$ & $-0.06 \pm 0.04$ & $0.00 \pm 0.04$ \\
\hline TOPL & $0.21 * \pm 0.03$ & $0.06 * \pm 0.03$ & $0.07 * \pm 0.03$ & $0.05 \pm 0.03$ & $0.14^{*} \pm 0.03$ & $0.07 * \pm 0.03$ & $0.03 \pm 0.04$ & $-0.05 \pm 0.04$ & $0.03 \pm 0.04$ \\
\hline TOT & $0.14 * \pm 0.03$ & $0.28 * \pm 0.03$ & $0.24 * \pm 0.03$ & $-0.09 * \pm 0.04$ & $-0.01 \pm 0.04$ & $-0.04 \pm 0.03$ & $-0.12 * \pm 0.04$ & $0.21 * \pm 0.04$ & $0.19 * \pm 0.04$ \\
\hline
\end{tabular}

See Table 1 for abbreviations. 
The genetic correlations between subjective conformation and objective traits were moderate to high and variable in sign. It is evident from the present results that heavier Merino sheep at Tygerhoek were generally plainer and had better scores for GEN, HOCKS and FQ as well as for TOPL, as suggested by significant genetic correlations between these traits. The genetic correlation between live weight and PS was also favourable but not significant. Previous studies on South African Merino sheep reported comparable genetic correlations of -0.24 and -0.26 between LW and TOT (Cloete et al., 1998; 2005). These correlations are regarded as favourable in view of plainer genotypes being preferred in South Africa at present. A corresponding favourable correlation (0.67) of LW with FQ was also reported for Cradock fine wool Merino sheep (Olivier et al., 2006b).

Unfavourable genetic correlations that occurred between TOT and fleece weights (GFW 0.48 and CFW 0.28) (Table 1) suggested that plainer sheep had generally lower fleece weights. Comparable genetic correlations between CFW and TOT of 0.19 (Cloete et al., 1998), 0.27 (Cloete et al., 2005) and 0.30 (Olivier et al., 2006b) have previously been reported for South African Merino sheep. On the contrary, previous research on Western Australian Merino sheep estimated favourable genetic correlations that ranged from -0.16 to -0.35 between wool weight and TOT, but with very high standard errors (Lewer et al., 1995). Furthermore, it was found that sheep with heavier fleeces generally had lower scores for TOPL, as suggested by the unfavourable $r_{g}$ between TOPL and fleece weights (-0.34 for GFW and -0.29 for CFW). Snyman \& Olivier (2002) reported a similar unfavourable relationship of -0.25 between TOPL and CFW in Afrino sheep. Sheep with stronger heads had higher clean fleece weights, as suggested by a significant genetic correlation between CFW and GEN (0.23). On the contrary, Snyman \& Olivier (2002) reported a negative genetic correlation of 0.18 between GEN and CFW in Afrinos. This discrepancy may be due to breed differences. While no significant genetic correlations were found between HOCKS and wool weights, Snyman \& Olivier (2002) estimated an unfavourable genetic correlation of -0.45 for CFW with HOCKS.

Estimates of $r_{g}$ were favourable for CY with GEN (0.25), with HOCKS (0.19) and with FQ (0.18), suggesting that sheep with a higher percentage of CY had stronger heads and higher scores for HOCKS and FQ. In contrast, Snyman \& Olivier (2002) reported an unfavourable correlation of CY with HOCKS (-0.23) in Afrino sheep. However, the present $r_{\mathrm{g}}$ between CY and FQ was consistent with that reported for Afrino sheep (Snyman \& Olivier, 2002). Research reported conflicting evidence on the direction and magnitude of the $r_{g}$ between CY and TOT for Merino sheep. Lewer et al. (1995) reported unfavourable correlations of CY with TOT that ranged from 0.01 to 0.28 for Western Australian Merino sheep, but with high standard errors. However, Cloete et al. (1998) reported a favourable correlation of -0.36 , which is somewhat higher than the present estimate of -0.26 on the same flock. The economic implication of the current results is that plainer sheep had a higher CY. Furthermore, PS and TOPL were not significantly related to CY in the current study. This accorded with results obtained for Afrino sheep (Snyman \& Olivier, 2002). A reduced FD would result in lower scores for HOCKS and TOT in Tygerhoek Merino flock, as suggested by the significant and unfavourable $r_{g}$ of 0.13 in both cases. Thus, plainer sheep would generally have a higher fibre diameter. Other studies on South African Merino sheep reported nonsignificant genetic correlations between FD and TOT (Cloete et al., 1998; 2005; 2006). In contrast, Lewer et al. (1995) reported favourable genetic correlations for FD with TOT, but with high standard errors. While FD was not significantly related to PS, TOPL and FQ in this study, Snyman \& Olivier (2002) reported a favourable correlation between FD and PS, and an unfavourable corresponding correlation of FD with TOPL. Also, Olivier et al. (2006b) reported an unfavourable genetic relationship between FD and FQ. FD was also not related to GEN and FQ in Carnarvon Afrino sheep (Snyman \& Olivier 2002), which is in good agreement with current results.

Estimates of $r_{g}$ were favourable for CVFD with HOCKS (-0.17), with FQ (-0.33) and with TOPL (-0.25). SDFD was significantly related to FQ (-0.20) and TOPL (-0.27) among the subjectively assessed conformation traits. At the genetic level, SL was favourably related to GEN (0.31) and TOT (-0.43), suggesting that, selection for an increased SL would result in plainer sheep with stronger heads. Previously, a nonsignificant correlation was reported between SL and GEN in Afrino sheep (Snyman \& Olivier, 2002), as well as for SL and TOT in the same Merino resource flock (Cloete et al., 1998). On the contrary, a significant correlation between SL and FQ was previously reported for Cradock fine-wool Merinos (Olivier et al., 2006a). An unfavourable $r_{g}$ of 0.25 
occurred between SS and TOT, thus plainer sheep would produce wool with weaker staples. The genetic correlation between SS and FQ was favourable.

Phenotypic correlations for LW and objective wool with subjective wool and conformation traits were low to high and variable in sign. Comparable estimates of phenotypic correlations were found in the literature for specific traits in Merino (Lewer et al., 1995; Cloete et al., 1998; Olivier et al., 2006a; b) and Afrino sheep (Snyman \& Olivier, 2002). Corresponding environmental correlations were also low to high and comparable in sign. In general, the phenotypic and environmental correlations of LW and objective wool traits with subjective wool and conformation traits were similar in sign but lower in magnitude. The only noteworthy maternal relationships were those for GEN with LW (0.74), of GEN with GFW (0.65) and of GEN with CFW (0.59).

\section{Conclusions}

Genetic parameters obtained in this study accorded with results of previous studies, in cases where comparable results were available. Most correlation estimates of LW and the objective wool traits with the subjective wool traits were favourable or nonsignificant. Selection for LW and objective wool traits will thus not seriously compromise the subjective wool traits. The exceptions are FD, CVFD and SDFD where unfavourable genetic correlations existed with STAPL and BANDP. Also, the present results were consistent with the present selection objectives in the South African Merino industry, favouring heavier and plainer breeding stock, supported by a favourable and moderate genetic correlation between LW and TOT. However, from these results it was clear that unrestrained discrimination against wrinkles in Merino sheep would adversely affect economically important objectively assessed wool traits such as SS, FD and wool weight. Selection against wrinkles should be carefully monitored to minimise the risk of animals producing reduced fleece weights with an increased fibre diameter. It is therefore, proposed that animals with excessive wrinkles be culled from the breeding stock. In addition a favourable relationship was found between TOT and CVFD. This relationship could be used to indirectly select against wool tenderness, based on the favourable genetic correlation of -0.57 between CVFD and SS (see Matebesi et al., 2009a). This contention is supported by the results of near optimal gains being achieved (Purvis \& Swan, 1999) when CVFD was included in the selection criterion as an indicator trait for SS.

\section{Acknowledgements}

The authors wish to express their profound gratitude and appreciation to KELLOGG foundation for funding this study. The technical assistance of E. du Toit and the Tygerhoek farmhands is also gratefully acknowledged.

\section{References}

Brown, D.J., Mortimer, R.L. \& Mortimer, M.L., 2006. Genetic aspects of greasy wool colour assessments in Merino sheep. Int. J. Sheep. Wool. Sci. 54, 1-16.

Cloete, S.W.P., Olivier, J.J. \& Du Toit, E., 1992. Linear type traits in a Merino flock subjected to selection for increased clean fleece mass and unselected control flock. S. Afr. J. Anim. Sci. 22, 70-73.

Cloete, S.W.P., Olivier, J.J., Snyman, M.A. \& Du Toit, E., 1998. Genetic parameters and trends in a selection experiment for increased clean fleece weight involving South African Merinos. Aust. J. Exp. Agric. 38, 427-432.

Cloete, S.W.P., Olivier, J.J. \& Van Wyk, J.B., 2006. Twenty years of divergent selection for reproductiongenetic parameter and genetic change. Proc. $41^{\text {st }}$ Congr. S. Afr. Soc. Anim. Sci. 131 (3-6 April 2006, Bloemfontein, South Africa).

Cloete, S.W.P., Olivier, J.J., Van Wyk, J.B., Schoeman, S.J. \& Erasmus, G.J., 2005. Genetic parameters and trends for hogget traits in Merino lines divergently selected for multiple rearing ability. Proc. Assoc. Advmnt. Anim. Breed. Genet. 16, 24-27. 
Crook, B.J., Piper, L.R. \& Mayo, O., 1994. Phenotypic associations between fibre diameter variability and greasy wool staples characteristics within Peppin Merino stud flocks. Wool Tech. Sheep Breed. 42, 304-318.

Fogarty, N.M., 1995. Genetic parameters for live weight, fat and muscle measurements, wool production and reproduction in sheep: a review. Anim. Breed. Abstr. 63, 101-143.

Gilmour, A.R., Gogel, B.J., Cullis, B.R., Welham, S.J. \& Thompson, R., 2002. ASREML-User Guide Release 1.0 VSN International Ltd, Hemel Hempstead, HPI IES, UK.

Gregory, I.P., 1982. Genetic studies of South Australian Merino sheep. IV. Genetic, phenotypic and environmental correlations between various wool and body traits. Aust. J. Agric. Res. 33, 363-373.

Lewer, R.P., Woolaston, R.R. \& Howe, R.R., 1995. Studies of Western Australian Merino sheep. III Genetic and phenotypic parameter estimates for subjectively assessed and objectively measured traits in ewe hoggets. Aust. J. Agric. Res. 46, 379-388.

Matebesi, P.A., Cloete, S.W.P. \& Van Wyk, J.B., 2009a. Genetic parameter estimation of 16-month live weight and objectively measured wool traits in the Tygerhoek Merino flock. S. Afr. J. Anim. Sci. 39, 73-82.

Matebesi, P.A., Van Wyk, J.B. \& Cloete, S.W.P., 2009b. Genetic parameters for subjectively assessed wool and conformation traits in the Tygerhoek Merino flock. S. Afr. J. Anim. Sci. 39, 176-187.

Morley, F.H.W., 1955. Selection for economic characters in Australian Merino sheep. V. Further estimates of phenotypic and genetic parameters. Aust. J. Agric. Res. 6, 77-90.

Naidoo, P., Cloete, S.W.P. \& Olivier, J.J., 2004. Heritability estimates and correlations between subjectively assessed and objectively measured fleece traits in Merino sheep. S. Afr. J. Anim. Sci. 34, 38-40.

Olivier, J.J., Delport, G.J., Erasmus, G.J. \& Eksteen, T.J., 1987. Linear type scoring in Merino sheep. Karoo Agric. 3, 1-4.

Olivier, W.J., Olivier, J.J. \& Greyling, A.C., 2006a. Correlations of subjectively assessed traits of fine wool Merino sheep with production and reproduction traits. Proc. $41^{\text {st }}$ Congr. S. Afr. Soc. Anim. Sci. 98 (3-6 April 2006, Bloemfontein, South Africa).

Olivier, W.J., Olivier, J.J., Cloete, S.W.P. \& Van Wyk, J.B., 2006b. Genetic analysis of the Cradock fine wool Merino stud. Proc. $8^{\text {th }}$ Wrld Congr. Gen. Appl. Livest. Prod. CD-ROM communication No. 5-09, 13-18 Aug., Brazil.

Purvis, I.W. \& Swan, A.A., 1999. Incorporating assessed style, length and strength into breeding objectives for fine and superfine Merino flocks. Proc. Assoc. Advmnt. Anim. Breed. Genet. 13, 177-180.

Safari, E., Fogarty, N.M. \& Gilmour, A.R., 2005. A review of genetic parameter estimates for wool, growth, meat and reproduction traits in sheep. Livest. Prod. Sci. 92, 271-289.

Snyman, M.A. \& Olivier, W.J., 2002. Correlations of subjectively assessed fleece and conformation traits with production and reproduction in Afrino sheep. S. Afr. J. Anim. Sci. 32, 88-96.

Snyman, M.A., Erasmus, G.J., Van Wyk, J.B. \& Olivier, J.J., 1995. Direct and maternal (co)variance components and heritability estimates for body weight at different ages and fleece traits in Afrino Sheep. Livest. Prod. Sci. 44, 229-235.

Young, S.S.Y., Turner, H.N. \& Dolling, C.H.S., 1963. Selection for fertility in Australian sheep. Aust. J. Agric. Res. 14, 460-482. 